\title{
Optimal Advertisement Placement Slot Using Knapsack Problem (A Case Study of Television Advertisement of Tv 3 Ghana)
}

\author{
Antony Kwarteng ${ }^{1}$, Ben Asante ${ }^{2}$ \\ ${ }^{1}$ The Department of Telecommunication Engineering, Ghana Technology University College, Ghana \\ ${ }^{2}$ The Department of Telecommunication Engineering, Ghana Technology University College, Ghana;
}

\begin{abstract}
It is undoubtedly that the major goal of many profit making organizations is to maximize their profits. And this is achieved by ensuring that some parameters such as time, materials, employees, among others are managed properly. In this paper, the research about how to model the TV3 advertisement selection problems as $0-1$ single knapsack problem so as to maximize the returns from their commercials is presented. Knapsack problem model is a general resource allocation model in which a single resource is assigned to number of alternatives with the aim of maximizing the total returns. In this work, the researcher obtained the data on TV3 adverts from the following zones: A1: TV3 News 360 (19:00 hours GMT) A4: Music - Music (20:30 - 21:30 GMT) every Saturday. A9: Mid-Day Live (12:00 - 12:30 GMT). Dynamic programming algorithm was used to solve the problem. To carry out the computations, the computer software, matlab was used to analyze the problem. The investigation revealed that the optimal income obtained from the various programmes in the study were all higher than what TV 3 management got when using their traditional methods of selection, (thus, the first company is served first, trial and error approach and the selections at the discretions of the administrators).
\end{abstract}

Keywords: knapsack, TV3, algorithm, advertisement, management, time

\section{INTRODUCTION \\ Background of the Study \\ One of the major problems confronting} most of the business organizations is how to allocate their scarce resources such as capital, people, time, etc., across projects or other type of investments. Most business organizations are profit making entities, so the allocation of their resources should be done so as to maximize the total returns from a given investment. Generally, the objective of the businesses is to select the particular parameter among others within a project so that when funded within the budget constrain will yield the best returns. Time is one of the greatest resources for Television and Radio stations. Broadcasting stations have to schedule programs interspersed with adverts or commercials. It is important to place adverts in such a way that the combination of adverts would have the largest exposure as possible so as to maximize the total returns. In order to achieve this goal, the broadcasting stations have to adopt appropriate scientific methods such as knapsack problem.

\section{History of Broadcasting in Ghana}

On the $31^{\text {st }}$. July, 1935, the then governor of the Gold Coast, Sir Arnold Hudson together with an electrical engineer, F. A. W Byron, initiated the establishment of a wired radio distribution system in Accra. It started as a department of the Ministry of Information which was charged with the responsibility for the formulation of national mass communication policies and also for ensuring the effective use of mass media for the dissemination of information, and for economic and social development of the country.

In the same year, the Ministry established a Radio Broadcasting station in the country with appropriately three hundred subscribers in Accra. Broadcasting began essentially as a relay service, re-broadcasting programmes from the BBC World Service. In 1936, the service began to expand and re-diffusion station was established in Cape Coast to cater to the people in the Central Region. In 1940, a new broadcasting house with $1.3 \mathrm{KW}$ transmission was built in Accra which could broadcast to the neighboring institutions. Broadcasting in four major local languages: Twi, Fanti, Ga and Ewe started in the same year.

In 1952, a commission was appointed to advise the government on ways of improving and developing broadcasting in the country. The commission was charged to investigate the establishment and maintenance of a statutory corporation to assume direction and control of broadcasting services as was the case of Britain. Based on the commission's recommendations, the national service of the Gold Coast Broadcasting was established in 1954.

In 1956, locally produced programmes were increased. Also educational broadcast to schools and teacher training colleges started. After the independent in 1957, the GOLD Coast 
Broadcast System became the Ghana Broadcasting System or Radio Ghana. Mass communication was embraced as a way of changing society. Broadcasting in Ghana was thus to be a public service dedicated to the enlightenment of the people. Since BBC was its main model, it adopted the public service model of BBC from the onset. In 1958, government of Ghana set another commission to give an advice on the launching of an external service of the Radio Ghana. As a result of the commission's recommendations, the external service of Radio Ghana was inaugurated in 1961. This was unusually bold step for a newly independent country. The external service came about primarily because the Prime Minister, Dr. Kwame Nkrumah saw the broadcasting as an opportunity to propagate his Pan African message to his fellow Africans.

Four years later, GBC Television Service was launched. In 1997, GBC entered into agreement with World space to GBC with a channel on its Afristar satellite to enable it provides a 24 - hour, Direct Digital Broadcasting (DDB) service over a coverage. Chapter 12 of the 1992 Constitution guarantees the freedom and independent of the media. Article 2 of 1992 Constitution explicitly prohibits censorship, while article 3 pre-empts any licensing requirements for mass media. Journalists welcomed the liberal provisions of the constitution, hailing the 1992 as a new era of free expression in Ghana. After the privatization of the airwave, the government gave approval for the allocation of frequencies to the private television stations as well. As a result, two private channels, TV3 and Metro TV went on air in 1997.

\section{Profile of TV 3 Ghana}

TV3 Network Ltd. (TV3 Ghana) is a private, free - to - air television broadcaster in Ghana which is owned by Malaysian median giant Media Prima. It was launched in Ghana in 1997. TV3 Ghana airs and produces a variety of television programmes including acclaimed news bulletins, dramas and successful reality television and entertainment shows. Some of the shows are apparently based on Malaysian programmes aired by television channels under Media Prima. For example, TV 3 Mentor was based on the TV3 Malaysia's singing competition, also titled Mentor. [1]. Media Prima claims that TV3 Ghana established itself as the most watched free - to- air television station in Ghana, having achieved $65 \%$ nationwide penetration at the end of 2006 and proposed to reach $90 \%$ of Ghanaians by 2008. [2] Media Prima is also expected to list TV3 Network Ltd. on the Ghana Stock Exchange by the first quarter of 2008.
However, TV3 experienced major competition in the like of Metro TV which succeeded not only in broadcasting its network to all the regions in the country but it also struck a deal with South Africa's Multichoice allowing it to broadcast throughout Africa. Despite this, TV3 remains popular for its showing of Mexican Telenovelas, Japanese series and music as compared to Metro's sports

\section{TV Broadcasting Programming or Scheduling}

Broadcasting scheduling is the act of organizing radio or television programmes in a daily, weekly or season-long schedule. Television scheduling strategies are adopted in such a way that the interest and satisfaction of the audiences would be reached and sustained. They are used to deliver programmes to audiences when they are most likely to want to watch them and deliver audiences to advertisers in the composition that makes their advertising most likely to be effective (Ellis, 2000).

\section{Television Commercials Scheduling}

As a business entity, every TV station has sources of income. One of the main sources of income for any private TV station is advertisement. The broadcasting is interspersed with advertising "breaks" normally three minutes long. In business, adverts are known as "spots". Typical spots last for $7,15,22,30,45,60,90,120$ seconds. In the advertising regulation, competing products should not be advertised within the same break. Hence, the product are scheduled into clash groups and products within the same group should not be advertised in the same break (Brown, 1969)

\section{Statement of the Problem.}

The main aim of every entrepreneur is to allocate his or her scarce resources in order to maximize their returns. One of the greatest resources of Television stations is 'Time'. Hence, it should be well managed so as to obtain a maximum returns. As a private television station, the main sources of income for TV 3 Ghana are advertisements and sponsorships, which operate within the time constraint. The administrators of the TV 3 face problems when selecting subsets of adverts or sponsors among the numerous adverts and sponsorships available that would earn them the optimal returns for the various programmes. The general practice is that, the selection is done by trial and error method at the discretions of the administrators. These approaches mostly do not yield maximum results. Television advertisement selection problems can be modeled as the knapsack problems. In this case, the advertisement would be considered as the items(x), whilst the charges and duration for each advert are the values (v) and 
weight (w) respectively. The total time available for advertisements would be the capacity (c) of the knapsack.

Knapsack problem models can be applied to many real life applications or industrial situations such as budgeting, cargo loading, cutting stock, etc.

\section{Objectives}

The objectives of the research are as follows:

to model advertisement scheduling as knapsack problems for TV3 station,

to maximize the returns from TV3 commercials.

\section{Justification}

Television stations play major roles in the political, educational and socio-development of the country. In order to discharge their functions well, the television stations need to generate enough revenue from the sponsored programs and advertisements to support their operations. It is important to place advertisements in such a way that the combination of advertisements would maximize the total returns. Without any adequate scientific methods of selecting from numerous advertisements received daily, the maximum returns from the advertisements may not be achieved.

The advertisements selecting problem can be modeled as knapsack problem and the appropriate algorithms could be applied as such, so that the maximum returns, is achieved. When this happens, it would enable the TV3 station to discharge its functions to the satisfaction of it cherish customers, which would justify its existence in the country. It may also lead to the expansion of the station, hence creating the employment for some people in the country. In addition, knapsack problem can model many other managerial and industrial situations such as capital budgeting problems, cargo loading, cutting stock problems and routing of vehicles etc.

\section{Limitations to the Study}

It was difficult to get all the data needed for the study because the management of TV 3 was not totally convinced that the data was going to be used solely for the purpose of research. As such they felt reluctant to provide them. Besides, the researcher was not given any data concerning their income. Furthermore, more time was wasted for going back and forth to TV3 for the data. And this traveling required money to do so.

\section{Methodology}

The problem considered in the survey was the modeling of advertisement selection problem as a single 0-1 knapsack problem that would yield optimal returns for television station as well as the entire media. For instance, suppose the producer of
TV 3 has $\mathrm{n}$ kinds of advertisement (items), 1 through $n$. Each kind of advertisement has a charge (value) and duration (weight). The maximum time allotted for the advert in the program is $\mathrm{C}$.

The problem can be modeled as a single 0-1 knapsack problem as shown below:

Let $x_{i}=$ the number of spots

$\mathrm{V}_{\mathrm{i}}=$ value (change) of the spots

$\mathrm{W}_{\mathrm{i}}=$ weight (duration) of the spots

$\mathrm{C}=$ the maximum time allotted for the advertisement is

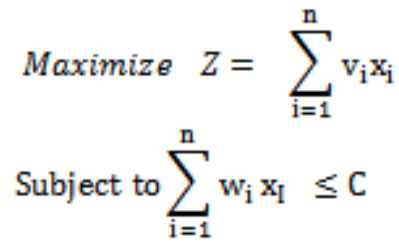

The data was collected from the office of TV3 Ghana Ltd.

Dynamic programming algorithm was used to solve the problem.

For the computation, computer software, matlab was used to analyze the problem.

Resources for the study were: library and internet.

\section{LITERATURE REVIEW}

Knapsack problems is notable for solving most of the industrial and managerial problems. In view of that, there have been many studies on it by both theorists and practitioners in recent Years. According to Zhong and Young, (2009) the integer programming tool and the Multiple Choice knapsack problems should be used to provide optimal solutions to transportation programming problems in cases where alternatives version of the project are under consideration. In the study, they compared the optimization methods, which are used in the transportation programming process and also discussed the process of building and solving the optimization problems. They presented the concept about the use of Multiple Choice Knapsack Problems (MCKP) and provided some examples of a real-world transportation

programming at various budget levels. Simoes et al., (2001) brought out an empirical study that compares the performance of the transposition -based Genetic Algorithm and the classical Genetic Algorithm for solving the $0-1$ knapsack problem. The results obtained showed that the transposition is always superior to crossover. According to Pendharker et al, (2005), the Information Technology Capital Budgeting, (ITCB) can be modeled as a 0-1 knapsack optimization problem. They further proposed two different simulation annealing (SA) heuristic solution procedures to solve the ITCB problems. They compared the performance of two SA heuristic procedure with the performance of two 
well-known ranking methods for capital budgeting. The results showed that the Information Technology (IT) investment chosen using the SA heuristic have higher after - tax profit than the IT investments selected using the two ranking methods.

Furthermore, Lin and Yao, (2001) studied knapsack problem whereby all of the weight coefficients are fuzzy numbers. The assumption used was that each weight coefficient is imprecise because of the use of decimal truncation or rough estimation of the coefficients by the decision maker. The main purpose of the study was to extend the original knapsack problem into more generalized problem that could be useful in practical situation. The study showed that the fuzzy knapsack problem is an extension of the crisp knapsack problem. Moreover, the crisp knapsack problem is a special case of the fuzzy knapsack problem.

Akinc, (2006) addressed the formulation and solution of a variation of the classical binary knapsack problem, "fixed- charge knapsack problem". In this problem, the sub-set of variables (activities) are associated with fixed costs. These costs may represent certain set-ups or preparation required for the associated sub-set of activity to be scheduled or both. He discussed several potential real-word applications as well as problem extensions or generalization. The efficient solution of a problem depends on a standard branch -and bound algorithm based on the following: (1) a nonnegative polynomial algorithm to solve the LP relaxation, (2) various heuristic to obtain good candidate solutions by adjusting LP solutions, and (3) powerful rules to peg variables. From the computational experience, the suggested brand and - bound algorithm shows excellent potentials in the solution of a wide variety of large fixed charge knapsack problems.

Again, Benisch et al, (2005), investigated the problem of choosing discriminatory prices for customer with probabilistic valuation and a seller with indistinguishable copies of goods. In the study, it revealed that under certain assumptions, the problem could be reduced to the continuous knapsack problem, (CKP). They presented a new fast epsilon - optimal algorithm for solving CKP instances asymmetric concave reward function. It was shown that the algorithm can be extended beyond the CKP setting to handling pricing problems with overlapping goods, rather than indistinguishable goods.

Bazgan et al, (2007), on their part presented approach, based on dynamic programming for solving0 - 1 multi - objectives knapsack problems. Their approach was based on the use of several complementary dominance relations to discard partial solutions that cannot lead to new non - dominated criterion vectors. They obtained an efficient method that performed better than the existing method, both in terms of CPU time and size of the solved instances. Extensive numerical experiments on various types of instances were reported. They also compared their approach with other exact methods Agali at el, (2009) considered the allocation of a limited budget to a set of activities or investments in order to maximize returns from the investments. In a number of practical contexts, the return from investment in an activity is effectively modelled using using an S-curve, where increasing returns to scale exist at small investment levels, and decreasing returns to scale occurs at high investment levels. Gerald et al, (2008) investigated some procurement problems where suppliers offer concave quantity discounts. The resulting continuous knapsack problem involves the minimization of a separable concave function.

Pisinger, (2007) gave a survey of upper bounds presented in literature. In the study, the relative tightness of several bounds was shown. The technique for deriving the bounds included the relaxation from upper planes, linearization, reformulation, lagrangian decomposition, lagrangian relaxation and semi definite programming. He also provided a short overview of heuristics, reduction technique, branch -andbound algorithms and approximation results, followed by an overview of the valid inequalities for the quadratic knapsack polytope. He concluded by an experimental study where the upper bounds presented were compared with respect to strength and computational effort.

Florios et al, (2009) solved instances of Multi-Objective Multi-Constraint knapsack problems from the literature. The problem involved three objective function and three constraints. They used both exact and approximate algorithms. Three branching heuristics and a more general purpose composite branching and construction heuristic were devised. The results from the exact algorithm showed that the branching heuristic greatly improved the performance of the Multi Criteria Branch and Bound algorithm, which becomes faster than adaptive. Zhang et al, (2004) came out with a simple but useful method, the core of which is an efficient LP-based heuristic, for solving biobjective 0-1 knapsack problems. The results of the computational experiments showed that the proposed method was able to generate a good approximation to the non-dominated set efficiently. In addition, they suggested three qualitative criteria to evaluate such an approximation. The method can be extended to other 
Balev et al, (2008) presented a preprocessing procedure for the 0-1 Multidimensional knapsack problem. They first generated nonincreasing sequence of upper bound by solving LP relaxation, followed by creating a non-decreasing sequence of lower bound using dynamic programming. The comparison of the two sequences allowed either to prove that the best feasible solution obtained is optimal or to fix a subset of variables to their optimal value. They also obtained a heuristic solution. The computational experiment with a set of large-scale instances showed the efficiency of their reduction scheme. Particularly, it was shown that their approach allowed the reduction of the CPU time of leading commercial software.

Taniguchi et al, (2008) introduced a kind of surrogated relaxation to derive upper and lower bound quickly and proved that, with this preprocessing, the similar pegging tests can be applied to our problem. The branch-and-bound algorithm can be use to solve the reduced problem to optimality. They used the surrogated variables to evaluate the upper bound at each branch-and-bound node very quickly by solving a continuous knapsack problem. The study showed that the developed method finds upper and lower bounds of very high accuracy in a few seconds and solves large instances to optimality faster than the previously published algorithms.

Marcquez et al, (2007) modeled an integer non-linear optimization problems and for which some heuristic methods were designed. Finally, computational experiments were given to analyze the methods.

Figuera et al, (2009) also investigated into a genetic labeling algorithm for finding nondominated outcomes of the multiple objective integer knapsack problems. The algorithm is used for solving the multiple objective shortest path problems on an underlying network. They presented the algorithms for constructing four network models. Every network consists of layers and network algorithm. When working forward layer by layer, they identified the set of all permanent non-dominated labels for each layer. The effectiveness of the algorithm is supported with numerical results obtained for the randomly generated problems for up to seven objectives. However, the exact algorithms in the literature solved the multiple objective binary knapsack problems with up to three objectives. It was realized that the approach could be applied to other classes of problems such as multiple constraints, binary variables, time depended objective functions, etc.

Elsevier et al, (2008) also introduced a utility model (UM) for resource allocation on computational grids. The allocation problem was formulated as a variant of the 0-1 multi-choice multidimensional knapsack problem. The notion of task option utility was introduced, and it was used to affect the allocation policies. They presented a variety of allocation policies, which were expressed as functions of metrics that are both intrinsic and external to the task and resources. The UM allocation strategy was shown to optimally allocate resource congruent with the chosen policies.

Okan et al, (2009) utilized admission control algorithms designed for revenue optimization with quality of service (QoS) guarantees to derive optimal pricing of multiple service classes in wireless cellular networks. A service provider typically adjusts pricing only periodically. Once a "global" optimal pricing is derived, it would stay static for a period, allowing users to be charge with the same rate while roaming. They utilized a hybrid partitioningthreshold admission control algorithm, to analyze a pricing scheme that correlates service demand with pricing, and to periodically determine optimal pricing under which, the system revenue is maximized while guaranteeing that QoS requirements of multiple service classes are satisfied.

Adlen et al (2007), proposed a new MAC protocol featuring a dynamic channel reservation by using dynamic TXOP limit parameter assignment, long with a fully distributed admission control algorithm. They generalized the model so that's fied. Each AC active in the network may a priory access the achievable QoS. The later model is used to design a fully distributed admission control algorithm that regulates the network load to protect the already admitted flows from the new entering flows. Simulation results showed that compared to both EDCA and AEDCF (adaptive EDCF), the protocol excels, in terms of network utilization and the ability to guarantee the same QoS metrics' performances to flow the same AC (intra-class).

Moraga et al, (2005) presented a solution approach, Meta-RaPS for the 0-1 Multidimensional knapsack problem. They implemented four different greedy priority rules within Meta-RaPS and compared them. Moreover, they implemented two simple local search techniques within MetaRaps' improvement stage. It was found that the Meta-RaPS approach performed better than many other solution methodologies in terms of differences from the optimal value and number of optimal solutions obtained. It was realized that Meta-RaPS approach is easy to

Freville et al., (2004) came out with an efficient preprocessing procedure for large-scaled instances. The algorithm provides sharp lower and 
upper bounds on the optimal value. It is also tighter equivalent representation by reducing the continuous feasible set and by eliminating constraint and variables. The scheme was proved to be very effective through a lot of computational experiment with test problems of the literature and large-scale randomly generated instances.

Ghorbani et al., (2009) studied a new multi-objective algorithm for project selection problem. They considered two objective functions to maximize total expect benefit of selected projects and minimized the summation of the absolute variation of allotted resources between each successive time-periods. A meta-heuristic multi-objective was proposed to obtained diverse locally non-dominated solutions. They compared the proposed algorithm, based on some prominent metrics with a well-known genetic algorithm, NSGA-II, the computational results showed that the proposed algorithm outperformed the NSGA-II.

Harper et al., (2001) presented a genetic algorithm as an aid for project assignment. The assignment problem was about the allocation of the projects to students. If the students are to choose from a list of projects in advance, inevitably, most students would prefer the more popular projects. Hence such project would be over-subscribed and assignment becomes a complex problem. The developed algorithm has compared well to an optimal integer programming approach. The main advantage of the genetic algorithm is that by its nature, the number of feasible project assignments can be produced, thus facilitating discussion on the merits of various allocations and supporting multiobjective decision making.

Gholamian et al., (2007) in their study, used a hybrid intelligent system instead of the mathematical model to solve the multi-objective problems. The main core of the system is fussy rule based, which maps decision space $(Z)$ to the solution space $(\mathrm{X})$. The system is designed on noninferior region and gives a big picture of this region in pattern of fussy rules. Since some of the solutions may be inferior, the specified feed forward network method is used to obtain noninferior solution in an exterior movement. They also provide numerical example as well-known NP-hard problems to clarify the accuracy of the developed system.

Again, Lin (2008) investigated the possibility of using genetic algorithms in solving the fuzzy knapsack problem without defining the membership functions for each imprecise weight coefficient. The proposed approach simulated a fuzzy number by distributing it into some partition points. The genetic algorithm was used to obtain the values in each partition point so that the final values represented the membership grade of the fuzzy number. The result of the study showed that the proposed approach performs better within the given bound of each imprecise weight coefficient than the fuzzy knapsack approach. The fuzzy genetic algorithm is different, but gave better results than the traditional fuzzy approach.

Balachandar et al., (2008) presented a heuristic to solve the 0-1 multi-constrained knapsack problem, which is NP-hard. In the study, they exploited the dominance property of the constraints to reduce the search space to near optimal solutions of $0-1$ multi-constrained knapsack problem. They also presented the space and computational complexity of solving 0-1 multiconstrained knapsack problems using that approach. The results from relative large size test problems showed that the heuristic can successfully be used for finding good solutions for highly constrained NP-hard problems.

Devyaterikova et al., (2009) presented discrete production planning problem, which may be formulated as a multidimensional knapsack problem. The resource quantities of the problem are supposed to be given as intervals. The approach to solve the problem based on using its relaxation set was suggested. Some L-class enumeration algorithms for the problem were described. They also presented the results of the computational experiments. The configuration of an optimization algorithm can make a significant difference to the efficiency of the solution process.

Gomes da Silva et al., (2007) studied the problem of inaccuracy in the solution generated by the Meta-heuristic approaches for combinatorial optimization bi-criteria 0-1 knapsack problems. They proposed a hybrid approach that combines systematic and heuristic searches to reduce that inaccuracy in a context in a scatter search method. They also presented the comparison of small and medium size instances to solve the exact methods. Large size instances were also considered and the quantity of the approximation method was evaluated by taken into account the proximity to the upper frontier, devised by the linear relaxation, and the diversity of the solutions. They also compared the approach with the other two wellknown meta-heuristic approaches. The results showed the effectiveness of the proposed approach for small, medium and large size instances.

Yield management is an essential issue in the television advertisement. The major parts in the research in the revenue management focus on the airline or hotel industry. For television advertisements, the offers are decomposed into small television breaks or spots. In the advertising regulation, the competing products should not be advertised within the same break. Hence, the scheduling products into clash groups such that the 
product in the same group are not advertised in the same break (Brown, 1969). Martin, (2004) proposed generic solution based on simulation and approximate.

Tsesmetzis et al, (2008) studied the problem of providers that receive multiple concurrent requests for services demonstrating different QoS properties. They introduced the "Selective Multiple Choice Knapsack Problem" that aims at identifying the services, which should be delivered in order to maximize the provider's profit, subject to maximum bandwidth constraints. The problem was solved by a proposed algorithm that had been empirically evaluated via numerous experiments.

Owoloko et al., (2010) studied into the application of the knapsack problem model to the placement of advert slots in the media. The aim was to optimize the capital allocated for advert placements. The general practice is that funds are allocated by trial and error and at the discretions of persons. This approach most time do not yield maximum results, lesser audience are reached. But when the scientific knapsack problem model was applied to industry data, a better result was achieved, wider audience and minimal cost was attained.

Oppong, (2009) considered the application of classical 0-1 knapsack problem with a single constraint to the selection of television advertisements at critical periods such as Prime Time News, news adjacencies and Peak times. The television stations have to schedule programmes interspersed with adverts or commercials, which are the main sources of incomes for the broadcasting stations. The goal in scheduling commercials is to achieve wider audience satisfaction in order to maximize the total returns. The approach is flexible and can incorporate the use of knapsack for the profit maximization in the television advert selection problem. The work was focused on the use of simple heuristic scheme (simple flip) for the solution of knapsack problems. It was shown that the results from the heuristic method compares favorably with the well-known meta-heuristic methods such as Genetic Algorithm and Simulation Annealing.

\section{METHODOLOGY TYPES OF KNAPSACK PROBLEMS AND SOLUTION}

Knapsack problems have known a large number of variations due to its wide range of applicability. Some of the variations are single and multiple-constrained knapsacks, knapsacks with disjunctive constraints, multidimensional knapsack, multiple choice knapsacks, single and multiple objective knapsack, integer, linear, non-linear knapsacks, deterministic and stochastic knapsacks with convex or concave objective functions etc.

The Subset Sum Knapsack Problem

The problem is $0-1$ problem as well as a decision problem with the values of items being the same as their respective weights.

The subset sum knapsack problem seeks to find from a given set of nonnegative integers, any subset of it that add up to exactly C.

The subset sum problem can be formulated as:

Let $v_{i}=$ the values of the ith item

$w_{i}=$ the weight of the ith item

$\mathrm{C}=$ the weight of the knapsack

But $v_{\mathrm{i}}=\mathrm{w}_{\mathrm{i}}$

Maximize $\mathrm{Z}=\sum_{\mathrm{i}=1}^{\mathrm{n}}\left(\mathrm{w}_{\mathrm{i}} \mathrm{x}_{\mathrm{i}}\right) \ldots \ldots \ldots \ldots \ldots \ldots .1$
Subject to $\sum_{\mathrm{i}=1}^{\mathrm{n}}\left(\mathrm{w}_{\mathrm{i}} \mathrm{X}_{\mathrm{i}}\right) \leq \mathrm{C} \ldots \ldots \ldots \ldots \ldots \ldots \ldots \ldots \ldots$

For $\mathrm{i}=1,2,3, \ldots, \mathrm{n}$

Let $\mathrm{x}_{\mathrm{i}}=\{0,1\}$ be the state of a piece of an item being included in the knapsack

$\left(w_{i}=1\right)$, if $x_{i}$ item is included and $\left(x_{i}=0\right)$, if $x_{i}$ item is excluded from the knapsack.

Equation 3.1 above gives the total value of items pack in a knapsack

$\left(x_{i}=1\right)$, if $x_{i}$ is included and $\left(x_{i}=0\right)$, if $x_{i}$ items are excluded from the knapsack.

Equation 3.1 above gives the total value of items packed in a knapsack, whereas equation 3.2 gives the maximum weight (capacity), the knapsack can take.

The change-making problem

It is a bounded knapsack problem in which the value of each item is one, (i.e $v_{i}=1$ )

In the capacity constraint, the equality is imposed instead of the inequality. This can be formulated mathematically as:

Let $\mathrm{w}_{\mathrm{i}}=$ the weight of ith item

$\mathrm{B}=$ the weight of knapsack

Maximize $Z=\sum_{\mathrm{i}=1}^{\mathrm{n}}\left(\mathrm{x}_{\mathrm{i}}\right) \ldots \ldots \ldots \ldots \ldots+3.3$

Subject to $\sum_{\mathrm{i}=1}^{\mathrm{n}}\left(\mathrm{w}_{\mathrm{i}} \mathrm{x}_{\mathrm{i}}\right)=\mathrm{b} \ldots \ldots \ldots \ldots \ldots . .4$

For $\mathrm{x}_{\mathrm{i}}=\{0,1\}$, and $\mathrm{i}=1,2,3, \ldots, \mathrm{n}$

The performance function (i.e equation 3.3), that gives the total values of the items packed in the knapsack is the same as total number of items packed in the knapsack since $v_{i}=1$. 
The constraint function (i.e equation 3.4), prescribes the maximum weight that the knapsack can take.

The problem recalls the situation of a cashier having to assemble a given change by using the maximum or minimum number of coins in denomination, $\mathrm{x}_{\mathrm{i}}$, hence the name the changemaking problem.

Multiple Knapsack Problems

It is 0-1 knapsack problem in which $m$ number of containers with given capacities $\mathrm{c}_{\mathrm{i}_{2}}$

$(\mathrm{i}=1,2,3, m)$ are available.

In this type of problem, each solution variable, $\mathrm{x}_{\mathrm{ij}}$, is restricted to only binary values, $x_{i j}=1$ if item $j$ is selected for the container $\mathrm{i}$, and 0 if otherwise.

The generalization arising when the item set is partitioned into subsets and the additional constraint is imposed that at most one item per item is selected. That type of problem is called the multiple-Choice Knapsack problem. The multiple choice knapsack problem is defined as a knapsack problem with additional disjoint multiple choice constraint. The general description of the problem is given as: there is one knapsack with limited capacity. The objects to be packed in the knapsack are classified into multiple mutually exclusive classes. Within each class there are several different items. The problem is to select some items from each class so as to minimize the total cost while the total size of items are does not exceed the limited capacity of the knapsack. This problem is to generalized carryout problem and is NP-hard The problem can be formulated mathematically as: Maximize $Z=\sum_{i=1}^{n} \sum_{j=1}^{n}\left(v x_{i j}\right) \ldots \ldots \ldots \ldots .5$ Subject to $\sum_{j=1}^{n} w_{i j} x_{i j} \leq c_{i} \ldots \ldots \ldots \ldots \ldots \ldots .6$ and $\sum_{\mathrm{i}=1}^{\mathrm{n}} \mathrm{x}_{\mathrm{ij}} \leq 1$ .3 .7

for $x_{j}=\{0,1\}, i=1,2,3, \ldots, n$, and $j=1,2,3, \ldots, n$. The gives performance function, 3.5 gives the total items packed in the knapsacks, whereas the constraints functions, 3.6 and 3.7 prescribe the various knapsacks.

\section{DATA MODELING}

The Single 0-1 Knapsack Problem

The single 0-1 knapsack problem is an integer programming problem with single constraint. In this problem, each solution variable is restricted to only binary values. For instance, in the following, we have $n$ kinds of items, 1 through $n$. Each kind of item has a values and weights are nonnegative. The maximum weight that we can carry in the bag is $\mathrm{C}$. The most common formulation of the knapsack problem is the 0-1 knapsack problem, which restricts the inclusion of ith item number to zero or one. Mathematically the 0-1 knapsack problem can be formulated through the following integer linear programming:

Let $v_{i}=$ the values of ith item

$w_{i}=$ the weight of ith item

$\mathrm{x}_{\mathrm{i}}=$ the number of pieces of ith items

$\mathrm{C}=$ the capacity of the knapsack

Maximize $\mathrm{Z}=\sum_{\mathrm{i}=1}^{\mathrm{n}}\left(\mathrm{v}_{\mathrm{i}} \mathrm{x}_{\mathrm{i}}\right) \ldots \ldots \ldots \ldots \ldots \ldots \ldots \ldots \ldots \ldots$

Subject to $\sum_{\mathrm{i}=1}^{\mathrm{n}}\left(\mathrm{w}_{\mathrm{i}} \mathrm{x}_{\mathrm{i}}\right) \leq \mathrm{C}$

For $\mathrm{i}=1,2,3, \ldots, \mathrm{n}$

Let $x_{i}=\{0,1\}$ be the state of a piece of item being included in the knapsack $\left(\mathrm{x}_{\mathrm{i}}=1\right)$, if $\mathrm{x}_{\mathrm{i}}$ item is included and $\left(x_{i}=0\right)$, if $x_{i}$ item is excluded from the knapsack.

Equation 3.1 above gives the total value of items packed in the knapsack, whereas equation a 3.2 gives the maximum weight (capacities), that the knapsack can take.

\section{Methods for solving Knapsack problems}

The two basic methods for solving 0-1 knapsack problems are Branch-and-Bound and Dynamic programming methods. Moreover, meta-heuristics such as simulated annealing, Genetic algorithm and Tabu search are used to solve large scale problems.

\section{Dynamic Programming Method}

The dynamic programming is a paradigm of algorithm design in which an optimization problem is solved by a combination of caching sub-problem solutions and appealing to the "principle of optimality." There are three basic elements that characterize dynamic programming algorithm namely: substructure, table-structure and bottom-up computation.

\section{a). Substructure}

Decompose the given problem into smaller (and hopefully simpler) sub-problems. Express the solution of the original problem in terms of solutions for smaller problems. Note that unlike divide-and-conquer problems, it is not usually sufficient to consider on decomposition, but many different ones.

\section{b). Table substructure}

After solving the sub-problems, store the answer (result) to the sub-problems in the table. This is done because (typically) sub-problems solutions are reused many times and we do not want to 
repeatedly solve the same problem over and over again

\section{c). Bottom up computation}

Using table, combine solutions of smaller subproblems to solve larger sub-problems, and eventually arrive at a solution to complete problems. The idea of bottom-up computation is as follows:

Start with the smallest sub-problems.

Combining their solutions, obtain the solution to sub-problems of increasing size.

iii. until one arrives at a solution of the original problem.

The dynamic programming approach can be used to solve knapsack problem provided certain integrality conditions of coefficient hold. The first assumption is that the coefficients $\mathrm{a}_{\mathrm{i}}$, $\mathrm{w}$ are positive integers, a dynamic programming algorithm construct a table of dimension $\mathrm{N}^{*}(\mathrm{~b}+1)$. The optimal solution may be found by backtracking through the table once the optimal value $\mathrm{P}_{\mathrm{N}}(\mathrm{b})$ is obtained. The complexity of this of this dynamic programming is $\mathrm{O}(\mathrm{Nb})$

The optimal solution may be found by backtracking through the table once the optimal value $\mathrm{pN}_{\mathrm{N}}(\mathrm{b})$ is obtained. The complexity of this dynamic programming is $\mathrm{O}(\mathrm{Nb})$. here the number of items, $\mathrm{I}=1,2, \ldots, \mathrm{n}$, are all positive integers.

Dynamic programming algorithm:

This algorithm is developed from the work created by Dr. Steve Goddard

Let $\mathrm{i}=\{1,2,3, \ldots, \mathrm{n}\}$

$w_{i}=$ weight of the ith item

$b_{\mathrm{i}}=$ the value of ith item

$\mathrm{W}=$ the maximum weight of the knapsack.

Step 1: Initialization

For $\mathrm{w}=0$ to $\mathrm{W}$ and $\mathrm{i}=1$ to $\mathrm{n}$

Let $\mathrm{B}[0, \mathrm{w}]=0$, and $\mathrm{B}[\mathrm{i}, 0]=0$

Step 2: for $\mathrm{i}=1$ to $\mathrm{n}$ and $\mathrm{w}=0$ to $\mathrm{W}$

Compute $\mathrm{B}[\mathrm{i}, \mathrm{w}]=\mathrm{b}_{\mathrm{i}}+\mathrm{B}\left[\mathrm{i}-1, \mathrm{w}-\mathrm{w}_{\mathrm{i}}\right]$; $\quad$ if $\mathrm{B}[\mathrm{i}, \mathrm{w}]>$

$\mathrm{B}[\mathrm{i}-1, \mathrm{w}]$ and $\mathrm{w}_{\mathrm{i}} \leq \mathrm{w}$

then the item, $i$ can be part of the solution in the table else, go to step 3

Step 3: if $w_{i} \leq w$ but $B[i, w] \leq B[i-1, w]$

compute $\mathrm{B}[\mathrm{i}, \mathrm{w}]=[\mathrm{i}-1, \mathrm{w}$.

Step 4: If $w_{i}>w$, compute $B[i, w]=[i-1, w]$

Repeat the process until all the data are considered.

Step 5: Select the maximum number from the solution table as the optimum solution.

Step 6: Select the knapsack items that gave the optimum solution:

Let $\mathrm{i}=\mathrm{n}$ and $\mathrm{k}=\mathrm{w}$

If $\mathrm{B}[\mathrm{i}, \mathrm{k}] \neq \mathrm{b}[\mathrm{i}-1, \mathrm{k}]$ then, mark the ith item as in the knapsack

$$
\begin{aligned}
& \mathrm{i}=\mathrm{i}-1 \text { and } \mathrm{k}=\mathrm{k}-\mathrm{w}, \text { else } \\
& \mathrm{i}=\mathrm{i}-1
\end{aligned}
$$

\section{DATA COLLECTION, ANALYSIS, AND REULTS}

\section{Data Collection}

The study into the selection of adverts at TV 3, Ghana Ltd was conducted. As a private entity, TV 3 is mandated to generate revenue for the upkeep of the station. In view of that, TV 3 has various ways of generating income. These may include sponsorship of programmes, social and funeral announcements and advertisements. However, the research was focused on the advertisements, which are slotted in the programme schedules prepared quarterly to generate revenue to sustain the operation of TV 3.

For the adverts, the rate structure and the programme schedule for the last quarter of 2010 was collected from the office of TV 3 Ghana Ltd. On the rate structure, the duration for the adverts have been zoned into ten zones i.e A1- A10. Each of the zones has different rate attached. If a programme is placed under zone A1, then it is considered to be among the most patronized programmes on the channel. Therefore, the advert charges for such programmes are very high. Similarly, the adverts charges for zone A10 programmes are very low as shown in the table 1 below. 
Table 1: TV 3 Rate Structure, (GH Cedis): It should be noted that the current rate may differ.

\begin{tabular}{|c|c|c|c|c|c|}
\hline Zone & $15 \mathrm{sec}$ & $20 \mathrm{sec}$ & $30 \mathrm{sec}$ & $45 \mathrm{sec}$ & $60 \mathrm{sec}$ \\
\hline A1 & GHd 375.86 & GHe 488.46 & GHd 734.46 & GHd 1084.29 & GHd 1.505 .49 \\
\hline A2 & GHd 334.10 & GHe 434.46 & GHd 652.86 & GHd 963.82 & GHd $1,338.22$ \\
\hline A3 & GHe 257.00 & GHe 344.20 & GHc 502.20 & GHd 741.40 & GHd 1029.40 \\
\hline A4 & GHC 197.70 & GHc 264.80 & GHd $386 . .30$ & GHৎ 570.40 & GHd 791.90 \\
\hline A5 & GHC 182.50 & GHc 246.90 & GHd 360.90 & GHc 532.40 & GHC 741.20 \\
\hline A6 & GHe 173.40 & GHe 228.20 & GHe 342.30 & GHe 513.00 & GHe 703.20 \\
\hline A7 & GHd 164.20 & GHd 208.80 & GHd 322.90 & GHd 457.50 & GHd 665.10 \\
\hline A8 & GHd 152.10 & GHd 205.30 & GHd 304.20 & GHd 456.30 & GHd 646.50 \\
\hline A9 & GHd 113.40 & GHd 141.60 & GHd 234.60 & GHe 354.00 & GHC 482.70 \\
\hline A10 & GHc98.70 & GHe 120.10 & GHe 200.30 & GHc 308.40 & GHc 416.10 \\
\hline
\end{tabular}

The data on TV 3 adverts were obtained from the following zones:

A1: TV 3 News 360 (19 hours GMT),

A4: Music - Music (20: 30 - 21: 30 GMT) every

Saturday.

A9: Mid-Day Live (12: 00 - 12: 30 GMT)
These data have been tabulated in table 2, 3 and 4 below.

Column 3 is duration per spot, column 4 is advert charges per spot $\left(v_{i}\right)$, column 5 is total duration In table 2, column 1 represents advert number, column 2 is the number of spots requested $\left(\mathrm{x}_{\mathrm{i}}\right)$, for the spots $\left(w_{i} x i\right) . I=\{1,2,3,4,5,6 \ldots 78\}$

Table 2: The Requested Adverts for TV 3 at $7.00-8.30 \mathrm{pm}$

Total Time Available is 1200 seconds

\begin{tabular}{|c|c|c|c|c|c|}
\hline \multicolumn{4}{|c|}{ Total Time Available is 1200 seconds } & \multicolumn{2}{|l|}{ Zone : A1 } \\
\hline $\begin{array}{l}\text { Adverts } \\
\text { №. }\end{array}$ & $\begin{array}{l}\text { No Of Spots } \\
\text { Requested, } \mathbf{x}_{1}\end{array}$ & $\begin{array}{l}\text { Duration } \\
\text { Per spot in } \\
\text { Second, } \boldsymbol{w}_{\mathbf{1}}\end{array}$ & $\begin{array}{l}\text { Advert } \\
\text { Charges per } \\
\text { Spot(GH } \phi), \mathbf{v}_{\mathbf{i}}\end{array}$ & $\begin{array}{l}\text { Total duration for } \\
\text { the } \\
\mathbf{w}_{\mathbf{1}} \mathbf{x}_{\mathbf{1}}\end{array}$ & $\begin{array}{l}\text { Amount, } \mathrm{GH} \phi \\
\mathbf{v}_{1} \mathbf{x}_{1}\end{array}$ \\
\hline 1 & 4 & 30 & 734.46 & 120 & 2937.84 \\
\hline 2 & 1 & 15 & 375.86 & 15 & 375.86 \\
\hline 3 & 3 & 60 & 1505.49 & 180 & 4516.47 \\
\hline 4 & 3 & 45 & 1084.29 & 135 & 3252.87 \\
\hline 5 & 3 & 20 & 488.76 & 60 & 1466.28 \\
\hline 6 & 4 & 30 & 734.46 & 120 & 2937.84 \\
\hline 7 & 3 & 45 & 1084.29 & 135 & 3252.87 \\
\hline 8 & 2 & 45 & 1084.29 & 90 & 2168.58 \\
\hline 9 & 3 & 20 & 488.76 & 60 & 1466.28 \\
\hline 10 & 4 & 60 & 1505.49 & 240 & 6021.96 \\
\hline 11 & 2 & 45 & 1084.29 & 90 & 2168.56 \\
\hline 12 & 3 & 60 & 1505.49 & 180 & 4516.47 \\
\hline 13 & 2 & 20 & 488.76 & 40 & 977.52 \\
\hline 14 & 5 & 15 & 375.86 & 75 & 1879.30 \\
\hline 15 & 2 & 15 & 375.86 & 30 & 751.72 \\
\hline 16 & 3 & 15 & 375.86 & 45 & 1127.58 \\
\hline 17 & 1 & 60 & 1505.49 & 60 & 1505.49 \\
\hline 18 & 1 & 20 & 488.76 & 20 & 488.76 \\
\hline 19 & 2 & 30 & 375.86 & 60 & 1468.92 \\
\hline 20 & 2 & 15 & 375.86 & 30 & 751.72 \\
\hline 21 & 3 & 45 & 1084.29 & 135 & 3252.87 \\
\hline 22 & 1 & 15 & 375.86 & 15 & 375.86 \\
\hline 23 & 4 & 30 & 734.46 & 120 & 2937.84 \\
\hline 24 & 2 & 45 & 1084.29 & 90 & 2168.58 \\
\hline 25 & 4 & 15 & 375.86 & 60 & 1503.44 \\
\hline 26 & 2 & 15 & 375.85 & 30 & 751.72 \\
\hline 27 & 3 & 45 & 1084.29 & 135 & 3252.87 \\
\hline 28 & 6 & 15 & 375.86 & 90 & 2255.16 \\
\hline Total & 78 & & & 2360 & 100123.47 \\
\hline
\end{tabular}


From the table 3, column 1 represents the advert number, column 2 is the number of spots requested $\left(\mathrm{x}_{\mathrm{i}}\right)$, column 3 is the duration per spot, column 4 is advert changes per spot $\left(v_{i}\right)$ column 5 is the total duration for the spot $\left(\mathrm{w}_{\mathrm{i}} \mathrm{x}_{\mathrm{i}}\right)$ and column 6 amount to be paid for each item $\left(\mathrm{v}_{\mathrm{i}} \mathrm{x}_{\mathrm{i}}\right) . \mathrm{I}=\{1,2,3,4,5 \ldots 59\}$

Table 3: Requested advert for TV 3 Music-Music Advert On Sat. 8.30-9.30 pm:

\begin{tabular}{|c|c|c|c|c|c|}
\hline \multicolumn{4}{|c|}{ Total Time Available is $1200 \mathrm{~s}$} & \multicolumn{2}{|c|}{ ZONE : A 4} \\
\hline \multirow{3}{*}{$\begin{array}{l}\text { Advert } \\
\text { №. } \\
1\end{array}$} & \multirow{3}{*}{\begin{tabular}{|c|}
\multicolumn{2}{|c}{ No. Of Spots } \\
Requested, S \\
$\mathbf{x}_{\mathbf{1}}$
\end{tabular}} & \multirow{3}{*}{\begin{tabular}{|lc|}
\multicolumn{2}{|l|}{ Duration Per } \\
Spots in \\
Second, $\mathbf{w}_{\mathbf{1}}$
\end{tabular}} & \multirow{2}{*}{$\begin{array}{l}\text { Charges Per } \\
\text { oft ( GH c), }\end{array}$} & \multirow{2}{*}{\multicolumn{2}{|c|}{$\begin{array}{c}\text { Total Duration Amount } \\
\text { For The Spotp, (Gh c) } \mathbf{v} / \mathbf{x}_{\mathbf{1}} \\
\mathbf{w}_{1} \mid \mathbf{x}_{1}\end{array}$}} \\
\hline & & & & & \\
\hline & & & 268.80 & 40 & 529.60 \\
\hline 2 & 4 & 15 & 197.70 & 60 & 790.80 \\
\hline 3 & 3 & 30 & 386.30 & 90 & 1158.90 \\
\hline 4 & 2 & 15 & 197.70 & 30 & 395.40 \\
\hline 5 & 1 & 15 & 197.70 & 15 & 197.70 \\
\hline 6 & 1 & 45 & 570.40 & 45 & 570.40 \\
\hline 7 & 3 & 20 & 268.80 & 60 & 806.40 \\
\hline 8 & 2 & 15 & 197.70 & 30 & 395.40 \\
\hline 9 & 4 & 15 & 197.70 & 60 & 790.80 \\
\hline 10 & 2 & 30 & 386.30 & 60 & 772.60 \\
\hline 11 & 2 & 60 & 791.90 & 120 & 1583.80 \\
\hline 12 & 1 & 20 & 268.80 & 20 & 264.80 \\
\hline 13 & 3 & 15 & 197.70 & 45 & 593.10 \\
\hline 14 & 2 & 30 & 386.30 & 60 & 772.60 \\
\hline 15 & 2 & 30 & 386.30 & 60 & 772.60 \\
\hline 16 & 3 & 45 & 570.40 & 135 & 1711.20 \\
\hline 17 & 3 & 20 & 268.80 & 60 & 794.40 \\
\hline 18 & 1 & 15 & 197.70 & 15 & 197.70 \\
\hline 19 & 2 & 30 & 386.30 & 60 & 772.60 \\
\hline 20 & 1 & 15 & 197.70 & 15 & 197.70 \\
\hline 21 & 3 & 45 & 570.40 & 135 & 1711.20 \\
\hline 22 & 3 & 15 & 197.70 & 45 & 593.10 \\
\hline 23 & 2 & 30 & 386.30 & 60 & 772.60 \\
\hline 24 & 1 & 30 & 386.30 & 30 & 386.30 \\
\hline 25 & 1 & 60 & 791.90 & 60 & 791.90 \\
\hline 26 & 1 & 20 & 268.80 & 20 & 264.80 \\
\hline 27 & 4 & 15 & 197.70 & 60 & 790.80 \\
\hline Total & 59 & & & 1460 & 29908.70 \\
\hline
\end{tabular}

From table 4, column 1 represents the advert number, column 2 is the number of spots

Requested $\left(\mathrm{x}_{\mathrm{i}}\right)$ : column 3 is the duration per spot $\left(\mathrm{w}_{\mathrm{i}}\right)$, column 4 is advert charges per spot $\left(\mathrm{v}_{\mathrm{i}}\right)$, Column 5 is total duration for the spots $\left(\mathrm{w}_{\mathrm{i}} \mathrm{x}_{\mathrm{i}}\right)$ and column 6 is the amount to be paid for each item $\left(\mathrm{v}_{\mathrm{i}} \mathrm{x}_{\mathrm{i}}\right) . \mathrm{i}=\{1,2,3,4,5 \ldots$ $36\}$.

Table 4: The Requested Adverts for Mid-Day Live at 12.00 - 12.30 pm Table 4

\begin{tabular}{|c|c|c|c|c|c|}
\hline \multicolumn{5}{|c|}{ Total Time Available is 600 Seconds } & ZONE:A9 \\
\hline $\begin{array}{c}\text { Adverts } \\
\text { No, } i\end{array}$ & $\begin{array}{c}\text { No of Spots } \\
\text { Requested } \\
(\mathrm{s}), \mathbf{x}_{\mathbf{1}}\end{array}$ & $\begin{array}{c}\text { Duration } \\
\text { Per Spot } \\
\text { In Seconds, } \mathbf{w}_{\mathbf{1}}\end{array}$ & $\begin{array}{c}\text { Advert } \\
\text { Charges per } \\
\text { Spot, } \mathbf{v}_{\mathbf{1}}\end{array}$ & $\begin{array}{c}\text { Total Duration } \\
\text { For The Spots }\end{array}$ & $\begin{array}{c}\text { Amount (GH c), } \\
/ \mathbf{v}_{\mathbf{1}} \mathbf{x}_{\mathbf{1}}\end{array}$ \\
\hline 1 & 2 & 30 & 234.60 & 60 & 469.2 \\
\hline 2 & 1 & 15 & 113.40 & 15 & 113.4 \\
\hline 3 & 2 & 15 & 113.40 & 30 & 226.8 \\
\hline 4 & 2 & 20 & 141.60 & 40 & 283.2 \\
\hline
\end{tabular}




\begin{tabular}{|c|c|c|c|c|c|}
\hline 5 & 3 & 30 & 234.60 & 90 & 703.8 \\
\hline 6 & 4 & 15 & 113.40 & 60 & 453.6 \\
\hline 7 & 1 & 45 & 354.00 & 45 & 354 \\
\hline 8 & 1 & 30 & 234.60 & 30 & 234.6 \\
\hline 9 & 3 & 20 & 141.60 & 60 & 424.8 \\
\hline 10 & 2 & 20 & 141.60 & 40 & 283.8 \\
\hline 11 & 2 & 45 & 354.00 & 90 & 708 \\
\hline 12 & 2 & 30 & 234.60 & 60 & 469.2 \\
\hline 13 & 1 & 30 & 234.60 & 30 & 234.6 \\
\hline 14 & 3 & 15 & 113.40 & 45 & 340.2 \\
\hline 15 & 1 & 45 & 354.00 & 45 & 354 \\
\hline 16 & 1 & 45 & 354.00 & 45 & 354 \\
\hline 17 & 3 & 15 & 113.40 & 45 & 340.2 \\
\hline 18 & 2 & 15 & 113.40 & 30 & 226.8 \\
\hline Total & 36 & & & 860 & 6754.2 \\
\hline
\end{tabular}

Model Formulation and Algorithm

From tables 2, 3 and 4, it could be seen that the total time (duration) demanded by the companies in each category exceeded the total available time for adverts. Hence, there is the need to select some subsets of adverts that would give maximum returns for the television station, so that the total time available for the adverts would not be exceeded.

The problem above can be formulated as a knapsack problem.

The following represent the general knapsack problem:

Maximise $Z=\sum_{\mathrm{i}=1}^{\mathrm{n}} \mathrm{v}_{\mathrm{i}} \mathrm{x}_{\mathrm{i}} \ldots \ldots \ldots \ldots \ldots \ldots 4.1$

Subject to $\sum_{\mathrm{i}=1}^{\mathrm{n}} \mathrm{w}_{\mathrm{i}} \mathrm{x}_{\mathrm{i}} \leq \mathrm{w}$

Where $\mathrm{i}=1,2,3 \ldots \mathrm{n}$,

Let $\mathrm{x}_{\mathrm{i}}=\{0,1\}$ be the state of an advert been included in the knapsack or not. $\mathrm{x}_{\mathrm{i}}=1$ if the ith advert is taken and $x_{i}=0$ if the ith advert is not taken.

Each table gives the number, $\mathrm{x}_{\mathrm{i}}$ of spots requested, the duration, $\mathrm{w}_{\mathrm{i}}$ for each advert, the charges, $v_{\mathrm{i}}$ of the adverts and the total time available, $\mathrm{W} \mathrm{x}_{\mathrm{i}}$ represents the column number two, $w_{\mathrm{i}}$ represents the column three and $v_{\tilde{i}}$ is column four in Tables 2 , 3 , and 4 above

$\mathrm{Z}$ represents the total income from the advertisements and $\mathrm{W}$ to be the total time available. Dynamic Programming Algorithm:

Dynamic programming algorithm was used to solve the above problem

From Table 2,3 and 4,

Let $\mathrm{x}_{\mathrm{i}}=$ column number two (i.e the number of spots requested) $\mathrm{w}_{\mathrm{i}}=$ column number three (i.e duration per spots seconds)

$v_{i}=$ column number four (i.e advert charges per spot)

$\mathrm{W}=$ the maximum available time for adverts on each programme
Algorithm
Let $\mathrm{i}=(1,2,3, \ldots \mathrm{n})$
$w_{i}=$ weight of the ith item
$v_{\mathrm{i}}=$ the value of the ith item
$\mathrm{W}=$ the maximum weight of the knapsack
Step 1: initialization
For $\mathrm{w}=0$ to $\mathrm{W}$ and $\mathrm{i}=1$ to $\mathrm{n}$
Let $\mathrm{B}[0, \mathrm{w}]=0$, and $\mathrm{B}[1,0]=0$ 
Step 2: For $\mathrm{i}=1$ to $\mathrm{n}$ and $\mathrm{w}=0$ to $\mathrm{W}$

Compute $\mathrm{B}[\mathrm{i}, \mathrm{w}]=\mathrm{b}_{\mathrm{i}}+\mathrm{B}\left[\mathrm{i}-1, \mathrm{w}-\mathrm{w}_{\mathrm{i}}\right] ; \quad$ if $\mathrm{B}[\mathrm{i}$,

$\mathrm{w}]>\mathrm{B}[\mathrm{i}-1, \mathrm{w}]$ and $\mathrm{w}_{\mathrm{i}} \leq \mathrm{w}$,

then the item, i can be part of the solution in the table.

Else, go to step 3

Step 3: If $w_{i} \leq w$ but $B[i, w] \leq B[i-1, w]$,

Compute B $[\mathrm{i}, \mathrm{w}]=\mathrm{B}[\mathrm{i}-1, \mathrm{w}]$

Step 4: If $w_{i}>w$, compute $B[i, w]=[i-1, w]$

Repeat the process until all data are considered.

Step 5: From the solution table, select the highest value to be the optimal solution.

Step 6: Select the knapsack items that gave the optimum solution:

Let $\mathrm{i}=\mathrm{n}$ and $\mathrm{k}=\mathrm{w}$

if $\mathrm{B}[\mathrm{i}, \mathrm{k}] \neq \mathrm{B}[\mathrm{i}-1, \mathrm{k}]$ then, mark the ith item as in the knapsack

$\mathrm{x}_{\mathrm{i}}=\{0,0,0,0,1,1,1,1,0,0,0,0,0,0,1,1,1,1,0,0,0,0,0,0,0,0,1,1,1,1,0,0,1,1,1,0,0,1,1,1,1,1,1$, $1,1,1,1,1,0,0,0,1,1,0,0,0,1,0,0,0,1,0,0,1,1,1,1,1,1,0,0,0,1,1,1,1,1,1\}$

Advert № $1=\mathrm{x}_{1}, \mathrm{x}_{2_{\mathrm{s}}} \mathrm{x}_{\mathrm{g}_{\mathrm{s}}}, \mathrm{x}_{4}$; № $2=\mathrm{x}_{5} ;$ № $3=\mathrm{x}_{6}, \mathrm{x}_{7}, \mathrm{x}_{\mathrm{g}} ;$ № $4=\mathrm{x}_{9}, \mathrm{x}_{10}, \mathrm{x}_{11} ;$ № $5=\mathrm{x}_{12}, \mathrm{x}_{19}, \mathrm{x}_{14} ;$ № $6=$ $\mathrm{x}_{15}, \mathrm{x}_{16,}, \mathrm{x}_{17}, \mathrm{x}_{19} ;$ №7 $=\mathrm{x}_{19,}, \mathrm{x}_{20}, \mathrm{x}_{21}$;№ $8=\mathrm{x}_{22}, \mathrm{x}_{23} \quad ; \quad$ № $9 \quad=\quad \mathrm{x}_{24}, \mathrm{x}_{25}, \mathrm{x}_{26}$; № $10=$

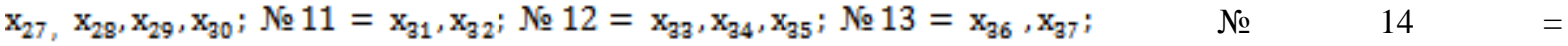
$\mathrm{x}_{19}, \mathrm{x}_{29}, \mathrm{x}_{40}, \mathrm{x}_{41}, \mathrm{x}_{42}$, № $15=\mathrm{x}_{49}, \mathrm{x}_{44} ;$ № $16=\mathrm{x}_{45}, \mathrm{x}_{46}, \mathrm{x}_{47} ;$ № $17=\mathrm{x}_{49} ;$ № $18=\mathrm{x}_{49} ;$ № $19=$ $\mathrm{x}_{50}, \mathrm{x}_{51} ;$ № $20=\mathrm{x}_{52}, \mathrm{x}_{58}$; № $21=\mathrm{x}_{54}, \mathrm{x}_{55}, \mathrm{x}_{56}$, № $22=\mathrm{x}_{57}$, № $23=\mathrm{x}_{58}, \mathrm{x}_{59}, \mathrm{x}_{60}, \mathrm{x}_{61}$;

№24 = $\quad \mathrm{x}_{62}, \mathrm{x}_{6 \mathrm{a}}$, № $25=\mathrm{x}_{64}, \mathrm{x}_{65}, \mathrm{x}_{66}, \mathrm{x}_{67} ; \mathrm{No} 26 \mathrm{x}_{68}, \mathrm{x}_{69} ;$ № $27=\mathrm{x}_{70}, \mathrm{x}_{71}, \mathrm{x}_{72} ;$ № $28=\mathrm{x}_{73}, \mathrm{x}_{74}, \mathrm{x}_{75}$, $\mathrm{x}_{76}, \mathrm{x}_{77}, \mathrm{x}_{78} \times$

The above results are tabulated in table 5 below

Table 5: The Results of TV 3 Adverts for News 360 At $7.00-8.00$ pm.

\begin{tabular}{|c|c|c|c|c|c|c|}
\hline & \multicolumn{4}{|c|}{ Total Time Available is 1200 seconds. } & \multicolumn{2}{|r|}{ Zone : A1 } \\
\hline $\begin{array}{c}\text { Advert } \\
\text { № }\end{array}$ & $\begin{array}{c}\text { No of spots } \\
\text { Requested, } \\
\mathbf{x}_{1}\end{array}$ & $\begin{array}{c}\text { No of } \\
\text { spots used }\end{array}$ & $\begin{array}{l}\text { Duration per } \\
\text { spot in } \\
\text { Second, } \boldsymbol{w}_{\mathbf{1}}\end{array}$ & $\begin{array}{c}\text { Advert } \\
\text { charges per } \\
\operatorname{spot}(\mathrm{GHc}), \mathbf{v}_{\mathbf{1}}\end{array}$ & $\begin{array}{l}\text { Total duration } \\
\text { for the } \\
\text { spots }(s), w_{1} \mathbf{x}_{\mathbf{1}}\end{array}$ & $\begin{array}{c}\text { Amount, (GHc } \\
), \\
\mathbf{v}_{\mathbf{1}} \mathbf{x}_{\mathbf{1}}\end{array}$ \\
\hline 1 & 4 & 0 & 0 & 0 & 0 & 0 \\
\hline 2 & 1 & 1 & 15 & 375.86 & 15 & 375.86 \\
\hline 3 & 3 & 3 & 60 & 1505.49 & 180 & 4516.47 \\
\hline 4 & 3 & 0 & 0 & 0 & 0 & 0 \\
\hline 5 & 3 & 0 & 0 & 0 & 0 & 0 \\
\hline 6 & 4 & 4 & 30 & 734.46 & 120 & 2937.84 \\
\hline 7 & 3 & 0 & 0 & 0 & 0 & 0 \\
\hline 8 & 2 & 0 & 0 & 0 & 0 & 0 \\
\hline 9 & 3 & 0 & 0 & 0 & 0 & 0 \\
\hline 10 & 4 & 4 & 60 & 1505.49 & 240 & 6021.96 \\
\hline 11 & 2 & 0 & 0 & 0 & 0 & 0 \\
\hline 12 & 3 & 3 & 60 & 1505.49 & 180 & 4516.47 \\
\hline 13 & 2 & 0 & 0 & 0 & 0 & 0 \\
\hline 14 & 5 & 5 & 15 & 375.76 & 75 & 1879.30 \\
\hline 15 & 2 & 2 & 15 & 375.86 & 30 & 751.72 \\
\hline 16 & 3 & 3 & 15 & 375.86 & 45 & 1127.58 \\
\hline 17 & 1 & 1 & 60 & 1505.49 & 60 & 1505.49 \\
\hline 18 & 1 & 0 & 0 & 0 & 0 & 0 \\
\hline 19 & 2 & 0 & 0 & 0 & 0 & 0 \\
\hline 20 & 2 & 2 & 15 & 357.86 & 30 & 751.72 \\
\hline
\end{tabular}




\begin{tabular}{|c|c|c|c|c|c|c|}
\hline 21 & 3 & 0 & 0 & 0 & 0 & 0 \\
\hline 22 & 1 & 1 & 15 & 375.86 & 15 & 375.86 \\
\hline 23 & 4 & 1 & 30 & 734.46 & 30 & 734.46 \\
\hline 24 & 0 & 0 & 0 & 0 & 0 & 0 \\
\hline 25 & 4 & 4 & 15 & 375.86 & 60 & 1503.44 \\
\hline 26 & 2 & 2 & 15 & 375.86 & 30 & 751.72 \\
\hline 27 & 3 & 0 & 0 & 0 & 0 & 0 \\
\hline 28 & 6 & 6 & 15 & 375.86 & 90 & 2255.16 \\
\hline Total & -78 & 42 & & & 1200 second & GHc 30005.00 \\
\hline
\end{tabular}

From column 7 of the table 5, the least amount charged for the selected adverts is GhC375.86 and the highest amount charged is GhC 4516.47.

The results revealed that adverts with numbers 1,4 , $5,7,9,11,13,18,19,21,24,27$, were not used as shown in the table 5.

For advert number 23, only one out of four requested adverts was considered. The optimal income of adverts from TV 3 News 360 is $\mathrm{GH} \phi$ 30,005.00.

Results for TV 3 Music- Music

From the table $3, i=\{1,2,3,4 \ldots 59\}$.

So $\mathrm{x}=\{0,1\}^{59}$

The computer analysis showed that the optimal returns of TV 3 adverts for Music-Music could be obtained when the following selection are made:

$\mathrm{x}_{\mathrm{i}}=\{1,1,1,1,1,1,1,1,1,1,1,1,1,1,1,1,1,1$, $1,1,11,1,1,1,1,1,1,1,1,1,1,1,1,1,0,0,0,0$, $1,1,1,1,1,1,0,0,0,1,1,1,1,1,1,1,1,1,1,1$, $1\}$

The above results are tabulated in table 6 below:

Table 6: Result of TV 3 Advert for Music-Music

\begin{tabular}{|c|c|c|c|c|c|c|}
\hline \multicolumn{5}{|c|}{ Total Time Available Is 1200s Available. } & \multicolumn{2}{|c|}{ ZONE: A 4} \\
\hline Advert № & $\begin{array}{c}\text { No of Spots } \\
\text { Requested, } \\
\mathbf{x}_{1}\end{array}$ & $\begin{array}{c}\text { No of Spots } \\
\text { used }\end{array}$ & $\begin{array}{c}\text { Duration } \\
\text { per Spots in } \\
\text { Second, } \\
\mathbf{w}_{\mathbf{1}}\end{array}$ & $\begin{array}{c}\text { Charges per } \\
\text { Spot }(\mathrm{GH} \phi), \\
\mathbf{v}_{\mathbf{1}}\end{array}$ & $\begin{array}{c}\text { Total } \\
\text { Duration For } \\
\text { The Spots, } \\
\mathbf{w}_{\mathbf{1}} \mathbf{x}_{\mathbf{1}}\end{array}$ & $\begin{array}{l}\text { Amount ( } \\
\text { GH } q), \mathbf{v}_{1} \mathbf{x}_{1}\end{array}$ \\
\hline 1 & 2 & 2 & 20 & 264.80 & 40 & 529.60 \\
\hline 2 & 4 & 4 & 15 & 197.70 & 60 & 790.80 \\
\hline 3 & 3 & 3 & 30 & 386.30 & 60 & 1158.90 \\
\hline 4 & 2 & 2 & 15 & 197.70 & 30 & 395.40 \\
\hline 5 & 1 & 1 & 15 & 197.70 & 15 & 197.70 \\
\hline 6 & 1 & 1 & 45 & 570.40 & 45 & 570.40 \\
\hline 7 & 3 & 3 & 20 & 268.80 & 60 & 806.40 \\
\hline 8 & 2 & 2 & 15 & 197.70 & 30 & 395.40 \\
\hline 9 & 4 & 4 & 15 & 197.70 & 60 & 790.80 \\
\hline 10 & 2 & 2 & 30 & 386.30 & 60 & 772.60 \\
\hline 11 & 2 & 2 & 60 & 791.90 & 120 & 1583.80 \\
\hline 12 & 1 & 1 & 20 & 264.80 & 20 & 264.80 \\
\hline 13 & 3 & 3 & 15 & 197.70 & 45 & 593.10 \\
\hline 14 & 2 & 2 & 30 & 386.30 & 60 & 772.60 \\
\hline 15 & 2 & 2 & 30 & 386.30 & 60 & 772.60 \\
\hline
\end{tabular}

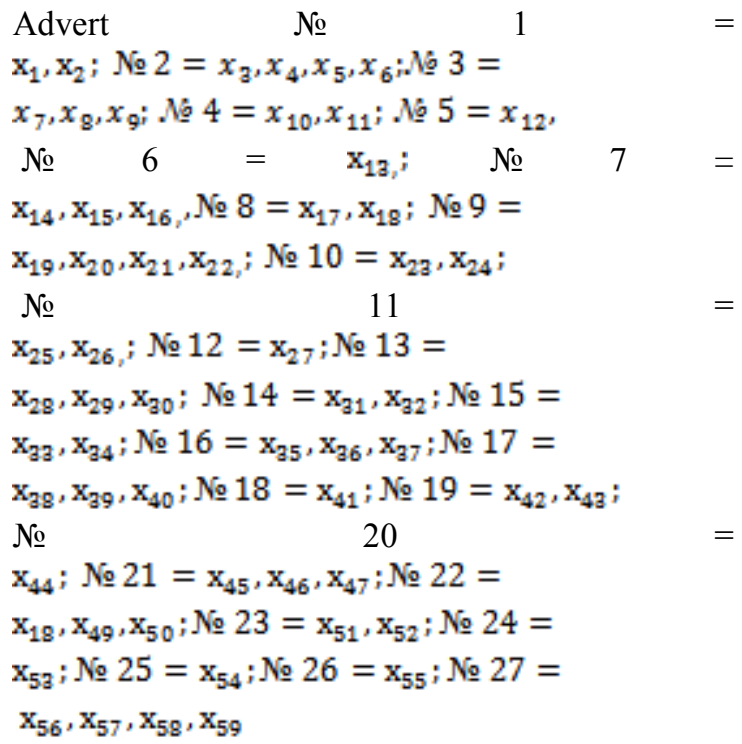




\begin{tabular}{|c|c|c|c|c|c|c|}
\hline 16 & 3 & 0 & 0 & 0 & 0 & 0 \\
\hline 17 & 3 & 2 & 20 & 264.80 & 40 & 529.60 \\
\hline 18 & 1 & 1 & 15 & 197.70 & 15 & 197.70 \\
\hline 19 & 2 & 2 & 30 & 386.30 & 60 & 772.60 \\
\hline 20 & 1 & 1 & 15 & 197.70 & 15 & 197.70 \\
\hline 21 & 3 & 0 & 0 & 0 & 0 & 0 \\
\hline 22 & 3 & 3 & 15 & 197.70 & 45 & 593.10 \\
\hline 23 & 2 & 2 & 30 & 386.30 & 60 & 772.60 \\
\hline 24 & 1 & 1 & 30 & 386.30 & 30 & 386.30 \\
\hline 25 & 1 & 1 & 60 & 791.90 & 60 & 791.90 \\
\hline 26 & 1 & 1 & 20 & 268.80 & 20 & 264.80 \\
\hline 27 & 4 & 4 & 15 & 197.70 & 60 & 790.80 \\
\hline Total & 59 & 52 & & & $1200 \mathrm{~s}$ & 15696.00 \\
\hline
\end{tabular}

From table 6 above, the least charge among the selected adverts is $\mathrm{GH} \notin 197.70$ whist the highest charge is $\mathrm{GH} \phi 1583.80$.

The results showed that adverts with numbers, 16 and 21 were not used. Besides, for the adverts number 17 , two out of three spots requested were used.

The optimal returns of TV 3 adverts from MusicMusic is $\mathrm{GH} \not 15,696.00$

Result of TV 3 Adverts for Mid-Day Live

From table $4, \mathrm{i}=\{1,2,3,4, \ldots, 36\}$

Let $\mathrm{x}_{\mathrm{i}}=\{0,1\}^{36}$

From the computer analysis, the optimal returns of the table 4 is obtained when the following selection are made, $\mathrm{x}_{\mathrm{i}},=\{1,1,0,0,0,0,0,1,1,1,1,1,1,1$,
$1,1,0,0,0,0,0,1,1,1,1,1,1,1,1,1,1,0,0,0,0$, $0\}$

$$
\begin{aligned}
& \text { Advert № } \quad 1= \\
& \mathrm{x}_{1}, \mathrm{x}_{2} ; \text { №2 } 2=x_{3} ; \text {, 스 } 3=x_{4}, x_{5} ; \text {, A } 4= \\
& x_{6}, x_{7} ; \text {, ․․ } 5=x_{8}, x_{9}, x_{10} ; x_{11} ; x_{12} \text {, }
\end{aligned}
$$

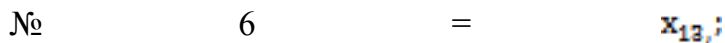

$$
\begin{aligned}
& \mathrm{x}_{14} ; \text { № } 7=\mathrm{x}_{15} ; \text { № } 8=\mathrm{x}_{16} ; \text { № } 9= \\
& \mathrm{x}_{17}, \mathrm{x}_{19}, \mathrm{x}_{19} ; \text { № } 10=\mathrm{x}_{20}, \mathrm{x}_{21} ; \text { № } 11=\mathrm{x}_{22} \mathrm{x}_{22, * ;} \\
& \text { № } 12 \\
& \mathrm{x}_{24}, \mathrm{x}_{25} \text {; № } 13=\mathrm{x}_{26_{g}} \text {; № } 14= \\
& \mathrm{x}_{27}, \mathrm{x}_{28}, \mathrm{x}_{29} ; \text { №15 }=, \mathrm{x}_{90} ; \text { № } 16=\mathrm{x}_{91} ; \text { №17= }
\end{aligned}
$$

\begin{tabular}{|c|c|c|c|c|c|c|}
\hline \multicolumn{5}{|c|}{ Total Time Available is 600s Available } & \multicolumn{2}{|c|}{ ZONE: A9 } \\
\hline Adverts № & $\begin{array}{c}\text { № of Spots } \\
\text { Requested(s), } \\
\mathbf{x}_{1}\end{array}$ & $\begin{array}{c}\text { № of Spots } \\
\text { Used }\end{array}$ & $\begin{array}{l}\text { Duration per } \\
\text { Spots in } \\
\text { Seconds, } \boldsymbol{w}_{\mathbf{1}}\end{array}$ & $\begin{array}{c}\text { Advert } \\
\text { charges per } \\
\text { Spotv }_{1}\end{array}$ & $\begin{array}{c}\text { Total } \\
\text { Duration For } \\
\text { The Spot } \mathbf{w}_{\mathbf{1}} \mathbf{x}_{1}\end{array}$ & $\begin{array}{l}\text { Amount } \\
\left(, \mathbf{G H} \not \mathbf{v}_{1} \mathbf{x}_{1}\right.\end{array}$ \\
\hline 1 & 2 & 2 & 30 & 234.60 & 60 & 429.20 \\
\hline 2 & 1 & 0 & 0 & 0 & 0 & 0 \\
\hline 3 & 2 & 0 & 0 & 0 & 0 & 0 \\
\hline 4 & 2 & 0 & 0 & 0 & 0 & 0 \\
\hline 5 & 3 & 3 & 30 & 234.60 & 90 & 703.80 \\
\hline 6 & 4 & 4 & 15 & 113.40 & 60 & 453.6 \\
\hline 7 & 1 & 1 & 45 & 354.00 & 45 & 354.00 \\
\hline 8 & 1 & 1 & 30 & 234.60 & 30 & 234.60 \\
\hline 9 & 3 & 0 & 0 & 0 & 0 & 0 \\
\hline 10 & 2 & 0 & 0 & 0 & 0 & 0 \\
\hline 11 & 2 & 2 & 45 & 354.00 & 90 & 708.00 \\
\hline 12 & 2 & 2 & 30 & 234.60 & 60 & 469.20 \\
\hline 13 & 1 & 1 & 30 & 234.60 & 30 & 234.60 \\
\hline 14 & 3 & 3 & 15 & 113.40 & 45 & 340.20 \\
\hline 15 & 1 & 1 & 45 & 354.00 & 45 & 354.00 \\
\hline 16 & 1 & 1 & 45 & 354.00 & 45 & 354.00 \\
\hline 17 & 3 & 0 & 0 & 0 & 0 & 0 \\
\hline 18 & 2 & 0 & 0 & 0 & 0 & 0 \\
\hline Total & 36 & 21 & & & $600 \mathrm{~s}$ & 4675.20 \\
\hline
\end{tabular}

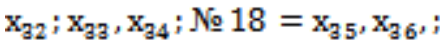

The above results are tabulated in table 7 below:

Table 7: The Results of TV 3 Advert For Mid-Day Live 
From the column 7 of the table above, the least amount charged for the selected adverts is

GHg 234.60, whilst the highest amount charged is $\mathrm{GH} \notin 708.00$

It could also be seen that the adverts with numbers; 2, 3, 4, 9, 10, 17 and 18 were not used.

The optimal returns of TV 3 Mid-Day life is $\mathrm{GH} \phi$ 4675.20

\section{SUMMARY, CONCLUSION, AND RECOMMENDATION}

\section{Summary}

The results for the analysis of data revealed that the optimal income of adverts from TV 3 News 360 is $\mathrm{GH} \varnothing 30,005.00$. The optimal income would be obtained when the programme managers select the adverts with the advert numbers:

$2,3,6,10,12,14,15,16,17,20,22,23,25,26,28$ as shown in the table 5 above.

For the advert № 23, the managers have to take only one out of the four adverts requested by the company.

Then also, the results shown that the optimal returns of adverts from TV 3 Music - Music programme is $\mathrm{GH} \phi 15,696.00$ and this would be obtained when the producers of TV 3 Music-Music programme choose the adverts with the numbers below:

$1,2,3,4,5,6,7,8,9,10,11,12,13,14,15,17,18$, 19, 20, 22, 23, 24, 25, 26, 27.

For the advert 17, two out of 3 requested adverts should be taken.

The results also revealed that the optimal incomes of adverts from TV 3 Mid-Day Live is $\mathrm{GH} \notin 4675.20$ and this would also be achieved if the producers of TV 3 Mid-Day Live select adverts with the numbers: $1,5,6,7,8,11,12,13,14,15$, 16.

The investigation revealed that these optimal incomes obtained from the various programs in the study were all higher than what TV 3 management got when using their traditional methods of selection, (thus, the first company is served first, trial and error approach and the selections at the discretions of the administrators).

\section{Conclusion}

From the study, the Television adverts selection problem was modeled as single $0-1$ knapsack problem as found in section 4.1 and 4.2 of the thesis. Using knapsack problem in adverts selection, the optimum returns of TV 3 News 360, Music-Music and Mid-Day Live programmes are $\mathrm{GH} \notin 30,005.00, \mathrm{GH} \phi 15,696.00$ and $\mathrm{GH} \phi 4,675.20$ respective, which are higher than the income obtained from the same adverts when using the traditional selection approaches, (trial and error, first come and first serve etc. ).

\section{Recommendations}

Since, the use of knapsack problem in television advert selection problems gives the optimum returns, it is recommends that the customer relation managers or programme producers of television stations should model their advert selection problems as knapsack problem so as to maximize their profits from the advertisements. The study considered the use of single 0 - 1 knapsack problem to solve adverts selection problems. Furthermore, it is recommended that there should be a future research on the application of other types of knapsack problems to solve Television advert selection problems.

\section{REFERENCES}

[1]. Abboud, N. J, Sakawa, M., Inuiguishi, M. (1997). A fuzzy programming approach to multiobjective multidimensional 0-1 knapsack problem. Linkinghub.elsevier.com/retrieve/pii/S01650 11495003622

[2]. Adlen, K., Abdelhamid, N., Abdelhak, G. and Mohammed N. (2007). A resource allocation protocol for QoS- sensitive services provisioning in 802. 11 networksPerformance Evaluation. Vol. 64. Pp. 416-443.

[3]. Alberto, C. and Michele, M. (2004). On the two dimensional Knapsack Problem. Operation Research Letters. http// www. mathtu-

dresden.de/belov/publdown1/2D/on2Dkp.cap rara_monaci. pdf

[4]. Anaud, F. and Gerald, P. (2004). An efficient preprocessing procedure for multidimensional 0-1 knapsack problem. http// portal.acm.org/citation.cfm?id=1460926 ..1k

[5]. Balanchandar, S. R. and Kannan, K. (2008). A new polynomial time algorithm for 0-1 multiple knapsack problems based on dominant principle.Journal of heuristics. Vol. 202(1). Pp. 71-77

[6]. Balev, S. (2008). The multidimensional knapsack problem. http//www.optimizationonline.org/DB FILE/2009/03/2258.PDF$31 \mathrm{~K}$

[7]. Beasley, J. E. (2002). Population heuristics. http://linkinghub.elsevier.com/retrieve/pii/S0 377221711002670--1k -

[8]. Benisch, M. and Greenwald, A. (2005). Pricing the customers with probabilistic Valuation. citeseerx .ist.psu.edu/viewdoc/summary?doi10.1.1179 .5875 .

[9]. Borteldt, A. and Hermann, G. (2001). A hybrid genetic algorithm for the container 
load problem. European Journal of Operation Research. Vol. 13(1). Pp. 143161.

[10]. Cai, Z. W. and Ong, H. L. (2004). Solving the biobjective zero- one knapsack problem by an efficient LP. www.faqs.org> Abstracts Index $>$ Business, international- Cached

[11]. Carlo, V. (1994). Constrained multi-project planning problems, Langrangean decomposition Approach. European Journal of operational Research. Vol. 78. Pp. 267275.

[12]. Caserta, M., quinonez, R., and Marquez, U. (2008). A cross entropy algorithm for the knapsack with setup. Computer and operational Research. Vol. 35. Pp. 241-252

[13]. Dantzig, G. B. (1957). Discrete-Variable Extremum problems. Journal of Operation Research. Vol. 5(2). Pp. 266-288.

[14]. Devyaterikova, M. V., Kolokolov, A. A. and Kolosov, A. P. (2009). L-class enumeration algorithms for a discrete production planning problem with interval resources quantities. European Journal of operation Research. Vol. 13(1). Pp. 143-161

[15]. Elsevier, B. V. (2009). Resource allocation on computational grids using a utility model in the knapsack problem. Future Generation Computer Systems. Vol. 25. Pp. 35- 50

[16]. Eugénia, M. C., João, C., José, F., Ernesto, M. and José, L.S., (2009). Solving bicriteria 0-1 knapsack problem using a labeling algorithm.

[17]. Florios, K. (2009). Solving multiobjectives, multiconstriant knapsack problems using mathematical programming and evolutionary. Iambda.qsensei.com/content/1 mblgq- Cached

[18]. Gholamian, M. R. (2001). A hybrid intelligent system for multi-objective decision

http://www.science/article/pii/S0950705106 001729

[19]. Halvard, A., Lars, M. H. and Arne, L. (2006). Adaptive memory search for multidemand multi-dimensional knapsack problem. Computer and Operating Research. http//www.portal.acm.org/citation.cfm?id=1 1410798 \& picked=prox

[20]. Li, V. C. and Curry, G. L. (2005). Solving multidimensional knapsack problems with generalized upper bound constraint using critical event tabu search. Computer and operational Research. Vol. 32. Pp. 825-848

[21]. Lin, F. T. and Yao, J. S. (2001). A survey of DEA and knapsack formulation application in project selection. European Journal of operation Research. Vol. 135 (1). Pp. 9
[22]. Lokketangen, A. and Fred, G. (1998). Solving 0-1 mixed integer programming problems using tabu search. European Journal of operational research. Vol. 106. Pp. 624-658.

[23]. Martello, S., Pisinger, D. and Paolo, T. (2000). New trends in exact algorithms for the $0-1 \quad$ knapsack problem. http//citeseerx.istpsu/viewdoc/download?doi 10. $1.11 .89068 \mathrm{rep}=$ rep $\mid$ type $=\mathrm{ps}$

[24]. Nazim, U. A. and Jatinder, N. D. (1987). An efficient heuristic algorithm for selecting project Computer and industrial Engineering Archives. Vol. 12. Pp. 153-158

[25]. Okan, Y . and Ing-Ray, C. (2009). Utilizing call admission control for pricing optimization of multiple service classes in wireless cellular networks. Computer Communications. Vol. 32. Pp. 317-323.

[26]. Oppong, E.O. (2010). Optimal Television Adverts Selection. http://www.maxwellsci.com/print/rjit/v3-4954-.pdf--1k

[27]. Owoloko, E. A. and sagoe, E, T. (2010). Optimal advert placement slot - using the knapsack problem model. American Journal of science and industrial research http//www.scihub.org/AJSIR. ISSN: 2153649X

[28]. Pati, H. K., Mall, R. and Sengupta, I. (2002). An efficient band width reservation and call admission control scheme for wireless networks. Computer Communications. Vol 25. Pp.74-83

[29]. Pendharkar, P. C. and Rodger, J. A. (2006). Information technology capital budgeting http://onlinelibrary.wiley.com/doi/10.1111/j. 1475-3995.2006...---1

[30]. Pisinger, D. (2001). Budgeting with bounded multiple choice constraint.

[31]. Journal of heuristics. Vol. 129. Pp. 471-480. Pisinger, W. D., Rasmussen, A. B. and Sandvik, R. (2007).

[32]. Solution of Large Quadratic Knapsack Problem Through Aggressive Reduction Informs. Journal on Computing, vol. 19(2). Pp 280- 290.

[33]. Realff, M. J., Kvam, P. H. and Taylor W. E. (1999). Combined analytical and empirical learning framework for branch and bound algorithms. citeseerx.ist.psu.edu/viewdoc/download?doi $=10.1 .1 .13$

[34]. Reinaldo, J. M. (2005). Meta-RaPS approach for the 0-1 Multidimensional Knapsack Problem. http://portal.acm.org/citation.cfm?id=16516 88- -1k 
[35]. Said, H. and Arnaud, F. (1998). An efficient tabu search approach for 0-1 multidimensional knapsack problem European Journal of operational Research. Vol. 106. Pp. 659-675

[36]. Silvano, M., pisinger D. and paolo T. (2000). New trends in exact algorithms for the 0-1 knapsack problem. http// citeseerx.ist.psu/viewdoc/download? doi 10 . 1. 11.89068rep=rep|\&type=ps

[37]. Simoes, A. And Costa, E. (2001). An immune system-based genetic http://portal.acm.org/citation.cfm?id=11442 09--1k

[38]. Dr. Steve Goddard. Data Structure and Algorithm.

http://www.cse.unl.edu/ goddard/Courses/C SCE31

[39]. Taniguchi, F. (2008). surrogate relaxation for deriving both upper and lower bounds efficiently.

http://imaman.oxfordjournals.org/content/19 /3/227.full.pdf- $-1 \mathrm{k}$

[40]. Tao, Z and Rhonda, Y. (2009). Multi Choice Knapsack Problem. Linkinghub.elsevier.com/retrieve/pii/S01497 $1890900041 x$

[41]. Theodore, S. G. and Stephen, V. A. (1973). Investment planning for irrigation development projects. Linkinghub.elsevier.com/retrieve/pii/003801 2173900505.

[42]. Umit, A. (2006). Approximate and exact algorithms for the fixed charged knapsack problem. Http:// www. mathu-dresden.delbelov/publ/down/kp_fixcharge pdf 